\title{
Hypertension outcomes of adrenalectomy in patients with primary aldosteronism: a systematic review and meta-analysis
}

\author{
Yu Zhou', Meilian Zhang ${ }^{2}$, Sujie Ke ${ }^{1}$ and Libin Liu'*
}

\begin{abstract}
Background: The hypertension cure rate of unilateral adrenalectomy in primary aldosteronism (PA) patients varies widely in existing studies.

Methods: We conducted an observational meta-analysis to summarize the pooled hypertension cure rate of unilateral adrenalectomy in PA patients. Comprehensive electronic searches of PubMed, Embase, Cochrane, China National Knowledge Internet (CNKI), WanFang, SinoMed and Chongqing VIP databases were performed from initial state to May 20, 2016. We manually selected eligible studies from references in accordance with the inclusion criteria. The pooled hypertension cure rate of unilateral adrenalectomy in PA patients was calculated using the DerSimonianLaird method to produce a random-effects model.

Results: Forty-three studies comprising approximately 4000 PA patients were included. The pooled hypertension cure rate was 50.6\% (95\% Cl: 42.9-58.2\%) for unilateral adrenalectomy in PA. Subgroup analyses showed that the hypertension cure rate was 61.3\% (95\% Cl: 49.4-73.3\%) in Chinese studies and 43.7\% (95\% Cl: 38.0-49.4\%) for other countries. Furthermore, the hypertension cure rate at 6-month follow-up was 53.3\% (95\% Cl: 36.0-70.5\%) and $49.6 \%$ (95\% Cl: 40.9-58.3\%) for follow-up exceeding 6 months. The pooled hypertension cure rate was 50. 9\% (95\% Cl: 40.5-61.3\%) from 2001 to 2010 and 50.2\% (95\% Cl: 39.0-61.5\%) from 2011 to 2016.
\end{abstract}

Conclusions: The hypertension cure rate for unilateral adrenalectomy in PA is not optimal. Large clinical trials are required to verify the utility of potential preoperative predictors in developing a novel and effective prediction model.

Keywords: Adrenalectomy, Hypertension, Primary aldosteronism, Meta-analysis, Review

\section{Background}

Primary aldosteronism (PA) is a group of disorders in which aldosterone production is inappropriately high for sodium status, relatively independent of the major regulators of secretion (e.g., angiotensin II, plasma potassium concentration), and is not suppressed by sodium loading [1]. Some studies have reported that PA is present in $>5 \%$ of hypertensive patients and may exceed $10 \%$ [2-4]. PA is typically caused by an adrenal adenoma and unilateral or bilateral adrenal hyperplasia. However, in a small proportion of cases, adrenal carcinoma and familial hyperaldosteronism can also precipitate PA.

\footnotetext{
* Correspondence: Libin.Liu@hotmail.com

${ }^{1}$ Department of Endocrinology, Fujian Medical University Union Hospital,

Fuzhou, Fujian 350001, China

Full list of author information is available at the end of the article
}

Idiopathic hyperaldosteronism (IHA) should be medically treated with a mineralocorticoid receptor antagonist, whereas unilateral primary aldosteronism, which includes aldosterone-producing adenoma (APA) and unilateral adrenal hyperplasia (UAH), is curable by surgical intervention [5]. However, after unilateral adrenalectomy, not all PA patients are completely cured of their hypertension, despite normalization of the biochemical marker abnormalities. After adrenalectomy for unilateral primary aldosteronism, complete hypertension cure rate and the factors associated with complete hypertension cure are variable. Previous studies have reported hypertension cure rates ranging from $35 \%$ to $63.8 \%$, with intrinsic risk factors being identified. These include age, gender, duration of hypertension, body mass index (BMI), and preoperative prescribing of antihypertensive agents [6-9]. Furthermore, a meta-analysis of 
the 25 studies with 1685 patients showed that the pooled proportion of normotension following adrenalectomy is $52 \%$ [10]. However, the study selects 25 articles which 4 Chinese studies only. A multicenter epidemiologic study in 11 provinces of China between January 2010 and October 2011 reveals that PA prevalence is 7.1\% among 1656 patients with resistant hypertension [11]. Given the high prevalence, PA patients in China are more and more interested in solving the problem of hypertension by adrenalectomy. Consequently, in the present study, we added the Chinese-language publication data and established more strict inclusion criteria to more comprehensively estimate the complete hypertension cure rate of unilateral adrenalectomy in PA patients.

\section{Methods}

\section{Literature search strategy}

Online retrieval of the following databases was conducted: PubMed, Embase, Cochrane, China National Knowledge Internet (CNKI), WanFang, SinoMed and Chongqing VIP. Eligible studies were manually selected from references according to the inclusion criteria. The search date was from initial state to May 20, 2016. The following keywords were used to identify potentially relevant studies from all databases: 'hyperaldosteronism' and 'adrenalectomy'. We also retrieved the references from all relevant publications to obtain further salient studies. Two independent reviewers ( $\mathrm{Yu}$ Zhou and Mei-Lian Zhang) conducted the literature screen of relevant titles and abstracts according to inclusion and excluding criteria. Su-jie Ke was the adjudicator for any articles that were disputed.

\section{Inclusion and exclusion criteria}

The following criteria were used for screening of the literature: (1) all PA patients to undergo unilateral adrenalectomy and sample size should be $\geq 20$; (2) study design comprised case-control and cohort studies; (3) the study provided the complete hypertension cure rate of unilateral adrenalectomy, or sufficient data for derivation of the pooled hypertension cure rate; (4) hypertension cure criteria was defined as normal blood pressure (systolic blood pressure (SBP) $<140 \mathrm{mmHg}$ and diastolic blood pressure (DBP) $<90 \mathrm{mmHg}$ ) without requirement for antihypertensive medications; (5) each study should provide a clear follow-up period; (6) the study was written in English and Chinese. Those studies which were not eligible for inclusion were excluded. If multiple published reports were from the same study cohort, we only included the study with the most detailed information and sample size.

\section{Extraction of data}

All data were extracted separately by the two aforementioned investigators. In the event of a dispute between the investigators, a discussion was conducted in order to arrive at consensus. Information obtained from each study included: author's first name, year of publication, country, years of inclusion, follow-up time, patients cured, patients followed up, cure rate (\%), pathological results, and study type.

\section{Statistical analysis}

This study was conducted and reported according to the recommendation of the Meta-analysis Of Observational Studies in Epidemiology (MOOSE) group [12]. Heterogeneity between the studies was estimated by calculating the $I^{2}$ statistic, which shows the percentage of variation between studies due to heterogeneity rather than by chance. $I^{2}<25 \%$ is considered low, $25-50 \%$ considered moderate, and $>50 \%$ is regarded as high-level heterogeneity [13, 14]. Given the high heterogeneity between studies, we used the DerSimonian and Laird method in generating the random effects models for the pooled estimation of prevalence. We conducted an analysis of subgroups to explore the potential sources of heterogeneity, including country (China and Other), follow-up time ( $\geq 6$ months and $<6$ months), number of patients followed up ( $\geq 50$ and $<50$ ), Publication Year (2001-2010 and 2011-2016), and pathology (APA Only and Other). Sensitivity analyses were conducted by excluding prospective studies. Funnel plots and the Egger test were used to test for publication bias. A $P$ value of less than 0.05 was considered statistically significant. All statistical calculations were performed using STATA, version 12 (STATA, College Station, TX). Ethics approval was not required as this was a secondary, literature-based study.

\section{Results}

\section{Literature search}

The literature search process is depicted in Fig. 1. The literature search initially yielded a total of 3410 articles, of which 691 duplicates were excluded and 2634 studies were removed after reviewing titles and abstracts. Thus, 85 studies were chosen for full-text assessment and critical appraisal. We excluded the cited articles for the following reasons: no follow-up period $(n=1)$; no hypertension cure criteria $(n=18)$; sample size $<20(n=4)$; article with overlapping data $(n=11)$; article with no calculation of cure rate $(\mathrm{n}=4)$; non-English language $(\mathrm{n}=1)$; Out of full-text $(n=3)$. Finally, there were 43 studies included in our meta-analyses [6-9, 15-53].

\section{Study characteristics}

The main characteristics from the included studies are shown in Table 1. The relevant number of patients followed up ranged from 20 to 376, with a total sample size of 3776. All studies were in Chinese and English. Studies were carried out in different countries, including the USA, China, Japan, Italy, Sweden, Germany, Australia, Czech Republic, Singapore and France. Forty of the included 


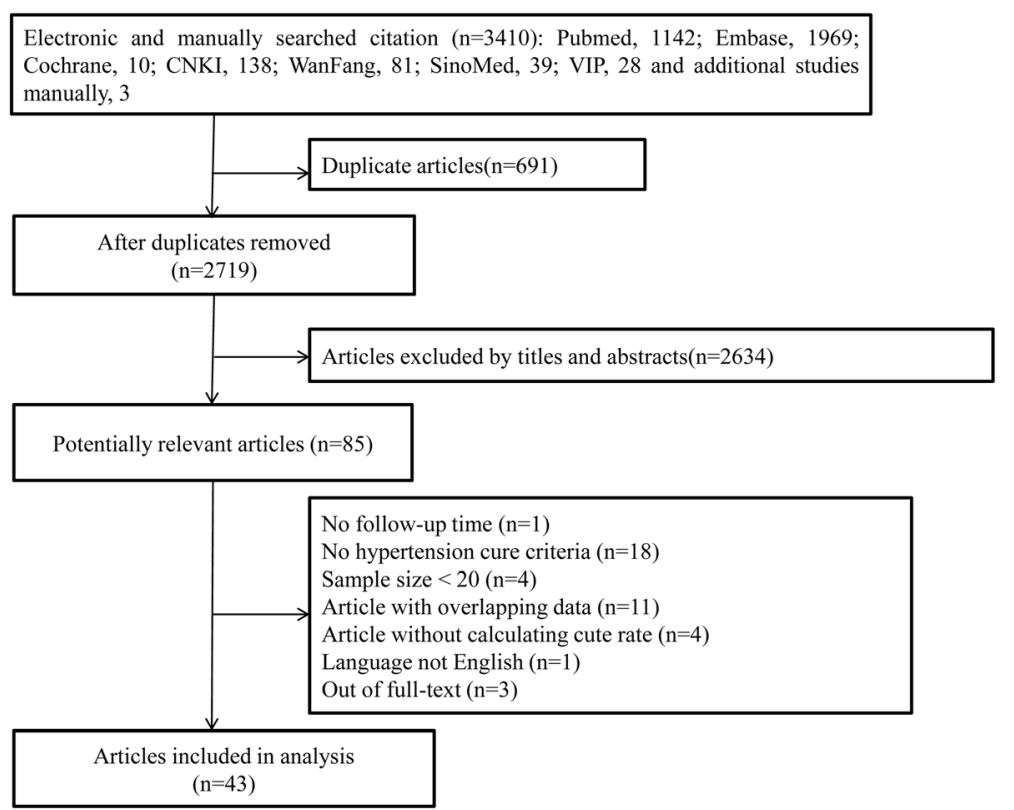

Fig. 1 Flow diagram of included/excluded studies

studies were methodologically retrospective. In contrast, only three studies were prospective cohort studies. All the cases were pathologically confirmed postoperatively.

Hypertension cure rate of unilateral adrenalectomy in PA Unilateral adrenalectomy in PA resulted in an overall hypertension cure rate that ranged between $15.0 \%$ and $96.0 \%$. The overall meta-analysis cure rate was $50.6 \%$ (95\% CI: 42.9-58.2\%; Fig. 2). The hypertension cure rate of unilateral adrenalectomy in PA also indicated a high level of heterogeneity between the studies $\left(\mathrm{I}^{2}=96.6 \%\right.$, $P<0.0001$ ).

The population of PA can be further stratified according to country (China and Other), follow-up time ( $\geq 6$ months and $<6$ months), patients followed up ( $\geq 50$ and $<50$ ), Publication Year (2001-2010 and 2011-2016), and pathology (APA Only and Other). The pooled hypertension cure rate of these subgroups is presented in Table 2. In the country setting, the hypertension cure rate of unilateral adrenalectomy in PA in China was 61.3\% (95\% CI: 49.4-73.3\%) from 1849 patients. The pooled cure rate from other countries (43.7\%, 95\% CI: $38.0-49.4 \%)$ was significantly lower than that reported in China (P for subgroup difference $<0.0001$ ). The hypertension cure rate of unilateral adrenalectomy for those followed up over a period of $<6$ months (53.3\%, 95\% CI: $36.0-70.5 \%)$ was higher than the group followed up over a period of $\geq 6$ months $(49.6 \%, 95 \%$ CI: $40.9-58.3 \%)$. The cure rate in the number of patients followed up being $<50$ (59.5\%, 95\% CI: 46.9-72.1\%) was significantly higher than that of the $\geq 50$ group $(46.6 \%$, 95\% CI: 37.4-55.7\%). The pooled hypertension cure rate did not change significantly over time. The pooled cure rate was 50.9\% (95\% CI: 40.5-61.3\%) from 2001 to 2010 , which was very similar to the rate of $50.2 \%$ (95\% CI: 39.0-61.5\%) from those studied in 2011 to 2016. In the postoperative pathology setting, there was no significant difference in the APA Only group (50.9\%, 95\% CI: 43.5-58.2\%) and the Other group $(50.4 \%, 95 \% \mathrm{CI}: 39.9-60.8 \%)$. The aforementioned subgroups had a high level of heterogeneity.

\section{Publication bias and sensitivity analysis}

From visual examination of the funnel plots, considerable publication bias was evident (Fig. 3). Probability for the Egger test was less than 0.001 . The sensitivity analysis was conducted by excluding the three prospective cohort studies and the results remained the same.

\section{Discussion}

Two reviews $[38,54]$ showed that the pooled cure rate of complete hypertension after unilateral adrenalectomy was $42 \%$ and $41 \%$, respectively. However, these reviews only included partial studies comprising at least 50 consecutive patients, and the potential sources of high-level heterogeneity could not be further explored. In addition, the inclusion of such studies can result in ill-defined postoperative hypertension cure criteria. Thus we performed a systematic evaluation of published studies on the hypertension cure rate of unilateral adrenalectomy in PA patients.

Compared to patients with essential hypertension, those with PA have been shown to have more frequent cardiovascular events, including myocardial infarction, stroke, and 
Table 1 Characteristics of the Included Studies

\begin{tabular}{|c|c|c|c|c|c|c|c|c|}
\hline Study,Year & Country & $\begin{array}{l}\text { Years of } \\
\text { Inclusion }\end{array}$ & $\begin{array}{l}\text { Follow-up } \\
\text { Time }\end{array}$ & $\begin{array}{l}\text { Patients } \\
\text { Cured }\end{array}$ & $\begin{array}{l}\text { Patients } \\
\text { Followed }\end{array}$ & Cure Rate(\%) & Pathology & Study Type \\
\hline Horita et al. 2001 [15] & Japan & 1977-1999 & $>6$ months & 13 & 26 & 50.0 & APA & retrospective \\
\hline Sawka et al. 2001 [16] & America & 1993-1999 & $0.1-77.9$ months & 31 & 93 & 33.3 & APA + Other & retrospective \\
\hline Fukudome et al. 2002 [17] & Japan & 1976-1998 & $1.2-23.1$ years & 34 & 46 & 73.9 & APA & retrospective \\
\hline Rossi et al. 2002 [18] & America & 1994-2000 & 1-63 months & 20 & 30 & 66.7 & APA + Other & retrospective \\
\hline Tan et al. 2002 [19] & China & 1984-2001 & $>3$ months & 44 & 46 & 95.7 & APA + Other & retrospective \\
\hline Goh et al. 2004 [20] & Singapore & 1996-2002 & $1-60$ months & 23 & 46 & 50.0 & APA + Other & retrospective \\
\hline Meyer et al. 2005 [21] & Germany & 1988-2001 & 38-134 months & 8 & 24 & 33.3 & APA + Other & retrospective \\
\hline Omura et al.2006 [6] & Japan & 1995-2005 & 1 year & 44 & 69 & 63.8 & APA & retrospective \\
\hline Han et al.2006 [22] & China & $2003-2005$ & 3-37 months & 35 & 47 & 74.5 & APA + Other & retrospective \\
\hline Pang et al.2007 [23] & Australia & 1995-2005 & $>1$ month & 18 & 53 & 34.0 & APA + Other & prospective \\
\hline Ziaja et al.2007 [24] & Poland & 1995-2005 & $1-10$ years & 10 & 31 & 32.3 & APA + Other & retrospective \\
\hline Walz et al.2008 [25] & Germany & 1994-2007 & $>1$ years & 48 & 160 & 30.0 & APA + Other & prospective \\
\hline Zarnegar et al.2008 [7] & America & 1994-2005 & $>6$ months & 35 & 100 & 35.0 & APA + Other & retrospective \\
\hline White et al.2008 [26] & America & 1996-2007 & $0.1-96.7$ months & 38 & 54 & 70.4 & APA + Other & retrospective \\
\hline Mourad et al.2008 [27] & France & 1997-1999 & 30-56 months & 23 & 58 & 39.7 & APA & retrospective \\
\hline Wu et al.2009 [8] & China & 1999-2007 & $>1$ year & 95 & 150 & 63.3 & APA & retrospective \\
\hline Chiou et al.2009 [28] & China & 1987-2006 & $>6$ months & 18 & 51 & 35.3 & APA & retrospective \\
\hline Campagnacci et al.2009 [29] & Italy & 1994-2006 & 20-128 months & 21 & 50 & 42.0 & APA & retrospective \\
\hline Wang et al.2010 [30] & China & $2002-2007$ & $1.2-5.3$ years & 54 & 93 & 58.1 & APA & retrospective \\
\hline Tresallet et al.2010 [31] & France & 1997-2008 & $>6$ months & 33 & 57 & 57.9 & APA + Other & retrospective \\
\hline Mathur et al.2010 [32] & America & NA & 1 month-9 year & 17 & 85 & 20.0 & APA + Other & retrospective \\
\hline Kim et al.2010 [33] & Korea & 1995-2008 & 6-159 months & 16 & 27 & 59.3 & APA & retrospective \\
\hline Fu et al.2011 [34] & China & $2000-2004$ & $>1$ years & 61 & 212 & 28.8 & APA & prospective \\
\hline Waldmann et al.2011 [35] & Germany & 1993-2009 & $>1$ years & 17 & 30 & 56.7 & APA + Other & retrospective \\
\hline Tang et al.2011 [36] & China & 1999-2009 & 6 months-2 years & 180 & 227 & 79.2 & APA + Other & retrospective \\
\hline Wang et al.2011 [37] & China & 2008-2010 & 1 week-1 year & 10 & 25 & 40.0 & APA + Other & retrospective \\
\hline Linden et al.2012 [38] & France & $2001-2009$ & 6-12 months & 68 & 156 & 43.5 & APA + Other & retrospective \\
\hline Wang et al.2012 [39] & China & 2008-2010 & $>6$ months & 43 & 83 & 51.8 & APA + Other & retrospective \\
\hline Wang et al.2012 [40] & China & 2009-2011 & 6-18 months & 17 & 20 & 85.0 & APA + Other & retrospective \\
\hline Wang et al.2012 [41] & China & 2002-2009 & $>6$ months & 44 & 82 & 53.7 & APA & retrospective \\
\hline Zhang et al.2013 [42] & China & 2005-2011 & $>6$ months & 207 & 376 & 55.1 & APA & retrospective \\
\hline Aronova et al.2014 [43] & America & 2004-2013 & $>1$ years & 21 & 47 & 44.7 & APA & retrospective \\
\hline Jiang et al.2014 [44] & China & 2004-2011 & 15-110 months & 88 & 164 & 53.7 & UAH & retrospective \\
\hline Lim et al.2014 [45] & China & 1993-2011 & 1.9-11.7 years & 127 & 133 & 95.4 & APA + Other & retrospective \\
\hline Wachtel et al.2014 [46] & America & 1997-2013 & $>1$ years & 13 & 85 & 15.3 & APA + Other & retrospective \\
\hline Hartmann et al.2014 [47] & Czech Republic & $2001-2011$ & 1 year & 17 & 51 & 33.3 & APA + Other & retrospective \\
\hline Utsumi et al.2014 [48] & Japan & 1995-2012 & $>6$ months & 56 & 132 & 42.4 & APA + Other & retrospective \\
\hline Wolley et al.2015 [49] & Australia & 2000-2014 & 6-24 months & 29 & 80 & 36.3 & APA + Other & retrospective \\
\hline Xie et al.2015 [9] & China & 2009-2014 & $0.17-5$ years & 43 & 94 & 45.7 & APA & retrospective \\
\hline Hu et al.2015 [50] & China & 2009-2014 & $>1$ years & 29 & 46 & 63.0 & APA + Other & retrospective \\
\hline Citton et al.2015 [51] & Italy & 1990-2013 & 1 month & 67 & 122 & 54.9 & APA + Other & retrospective \\
\hline Volpe et al.2015 [52] & Sweden & 1985-2010 & $0.5-26$ years & 46 & 120 & 38.3 & APA + Other & retrospective \\
\hline Fujita et al.2016 [53] & Japan & 2000-2015 & $>1$ years & 36 & 95 & 37.9 & APA + Other & retrospective \\
\hline
\end{tabular}




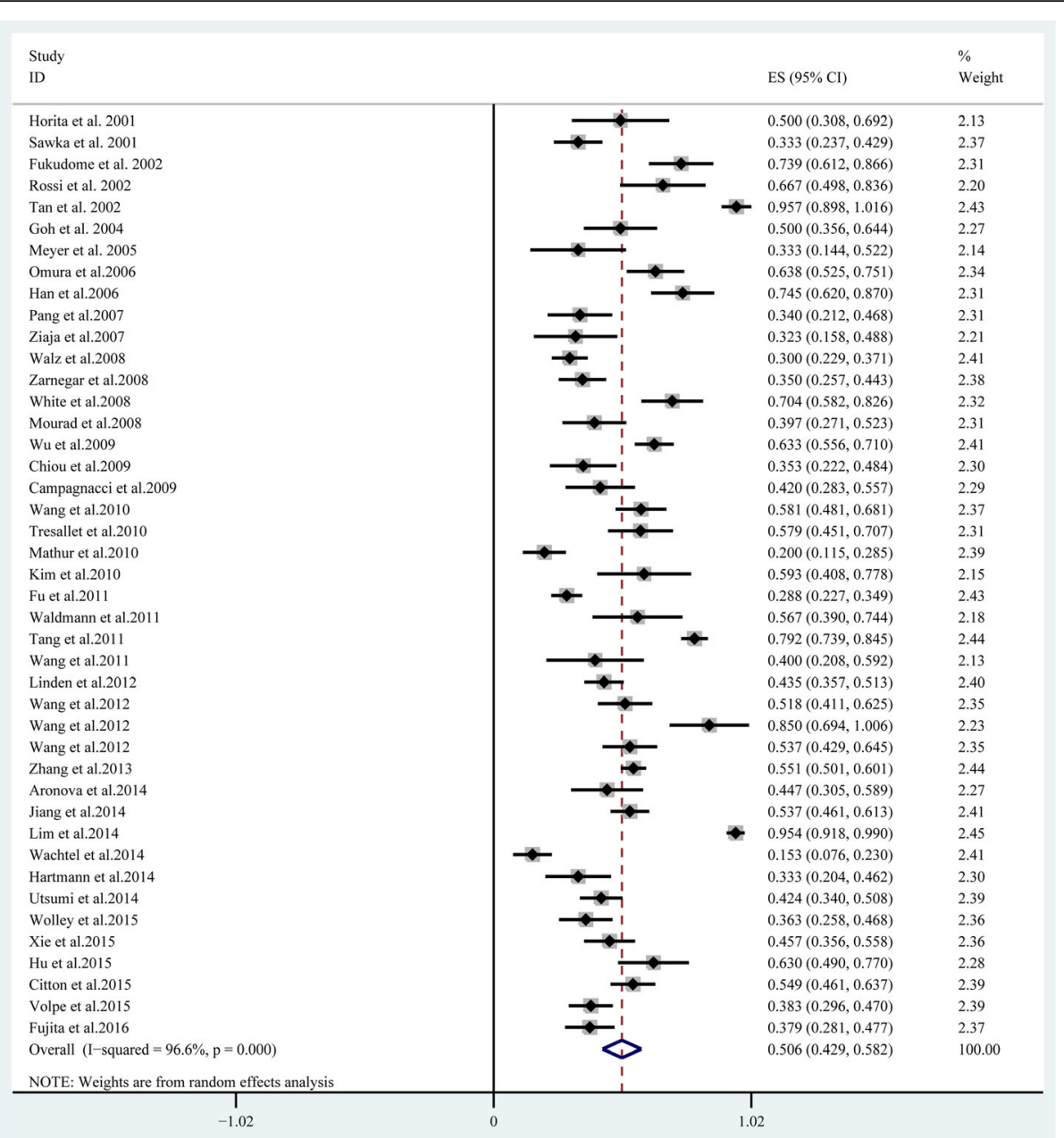

Fig. 2 Forest plot of hypertension cure rate of unilateral adrenalectomy for all PA patients

atrial fibrillation $[55,56]$. This higher incidence may be associated with aldosterone-driven excess left ventricular hypertrophy (LVH), myocardial fibrosis and endothelial dysfunction in PA patients [57-59]. Localization of the source of excessive aldosterone secretion is critical in guiding the management of PA. A biochemical cure with normalization of hypokalemia and aldosterone levels is almost certain following adrenalectomy [7], however, not all patients are completely cured of hypertension after adrenalectomy. This suggests that blood pressure alone is

Table 2 Hypertension cure rate of unilateral adrenalectomy by different categories

\begin{tabular}{lllllll}
\hline Category & Subgroup & NO. of Studies & Cute Rate $(95 \% \mathrm{Cl})(\%)$ & $N$ & $\mathrm{I}^{2}(\%)$ & $P$ \\
\hline Country & China & 16 & $0.613(0.494-0.733)$ & 1849 & 97.5 & $<0.0001$ \\
& Other & 27 & $0.437(0.380-0.494)$ & 1972 & 85.9 & $<0.0001$ \\
Follow-up Time & $\geq 6$ months & 32 & $0.496(0.409-0.583)$ & 3081 & 96.7 & $<0.0001$ \\
& $<6$ months & 11 & $0.533(0.360-0.705)$ & 695 & 96.6 & $<0.0001$ \\
Patients Followed & $>50$ & 29 & $0.466(0.374-0.557)$ & 3285 & 97.2 & $<0.0001$ \\
& $<50$ & 14 & $0.595(0.469-0.721)$ & 491 & 91.3 & $<0.0001$ \\
Publication Year & $2001-2010$ & 22 & $0.509(0.405-0.613)$ & 1396 & 94.9 & $<0.0001$ \\
& $2011-2016$ & 21 & $0.502(0.390-0.615)$ & 2380 & 97.5 & $<0.0001$ \\
Pathology & APA Only & 14 & $0.509(0.435-0.582)$ & 1381 & 86.3 & $<0.0001$ \\
& Other & 29 & $0.504(0.399-0.608)$ & 2395 & 97.4 & $<0.0001$ \\
\hline
\end{tabular}




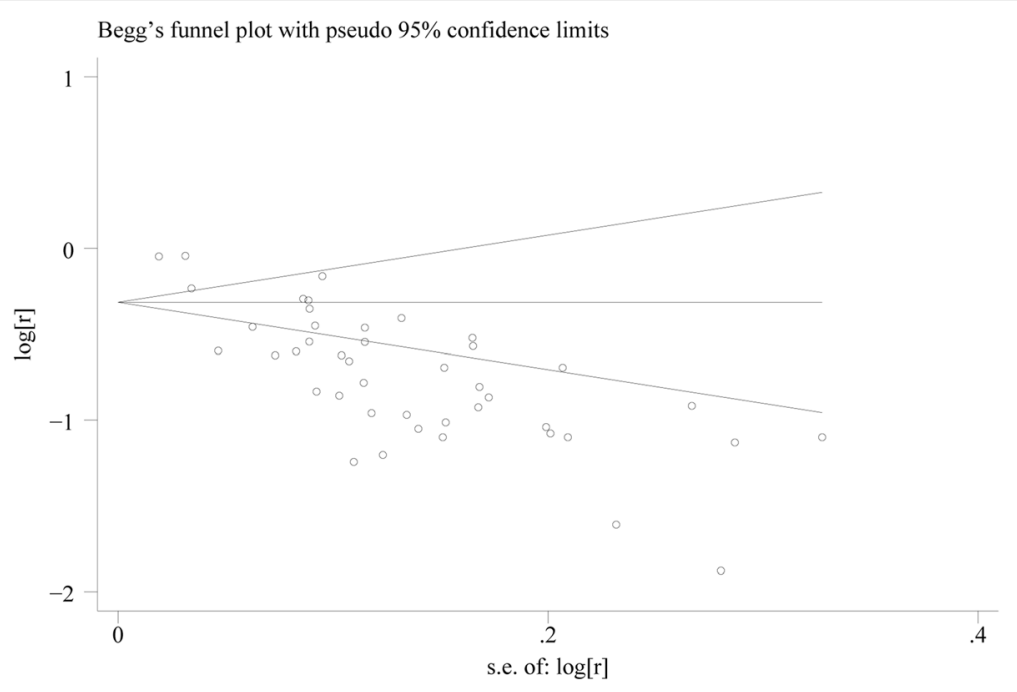

Fig. 3 Begg funnel plot for hypertension cure rate of unilateral adrenalectomy

probably not a good outcome of interest in PA studies when viewed in isolation. Complete cure of hypertension as a binary benefit/no benefit variable is an oversimplification. Many patients would perceive achieving control of blood pressure and a large reduction in medications as worthwhile. Additional quality of life benefits have been reported, as have very recent metabolic effects.

In PA patients, surgical treatment is associated with quicker resolution of hypertension, shorter length of hospital stay, and decreased cumulative costs compared with lifelong medical therapy [11]. Most PA patients want a definitive prognosis regarding postoperative probability of hypertension cure when they consider surgical intervention. If such a prognosis could be calculated more precisely, surgeons would be able to explain postoperative hypertension outcome to PA patients with more confidence. In our meta-analysis, a total of 43 studies encompassing approximately 4000 PA patients were included. We found a pooled hypertension cure rate of 50.6\% (95\% CI: $42.9-58.2 \%$ ) for unilateral adrenalectomy in PA patients. For different subgroups, the hypertension cure rate of unilateral adrenalectomy in PA was within the range of $43.7 \%$ to $61.3 \%$. In the country setting, the pooled hypertension cure rate of unilateral adrenalectomy in PA reported by other countries was lower than that reported in China, most likely caused by the different extent in postoperative follow-up. Wachtel [46] demonstrated that the cure rate at long-term followup ( $\geq 12$ months after surgery) was different from that of short-term follow-up (6-12 months after surgery). This may be associated with a slower return to physiologically normal state. Our study confirmed this: the hypertension cure rate of unilateral adrenalectomy for a follow-up time $<6$ months was higher than that for patients followed up over a period of $\geq 6$ months. We also found that sample size affected the hypertension cure rate. The cure rate in the number of patients followed being $<50$ was higher than that for the number of patients $\geq 50$. The difference between the 2 periods (2001-2011 and 2011-2016) could be explained by an analysis of the type of imaging method used for the diagnostic and tree use of catheterism for adrenal vein samplings (AVS).

Given that the hypertension cure rate of unilateral adrenalectomy was not particularly high, it is necessary to preoperatively forecast hypertension outcome of unilateral adrenalectomy in PA patients. In an effort to more appropriately select candidates for surgery, previous studies have suggested a number of potential preoperative predictors for postoperative hypertension cure in PA patients. These include age, gender, BMI, duration of hypertension, family history of hypertension, preoperative number of antihypertensive agents and others. However, several studies have found no association with hypertension cure for each of the aforementioned predictors. Zarnegar et al. [7]. developed the Aldosteronoma Resolution Score (ARS), which was composed of 4 predictors (number of antihypertensive drugs, BMI, duration of hypertension, and gender), to predict hypertension outcome of adrenalectomy in PA patients. Furthermore, Steichen et al. [54] pointed out that the ARS models were the only prediction model validated to date, and provided only a weak prediction of hypertension cure in individual patients. According to the ARS models, even if none of these features was present in an individual patient, the patient still had a $25 \%$ probability of being completely cured by adrenalectomy. In this systematic review, due to the inconsistent data pertaining to risk factors and outcome, we could not obtain a pooled odds ratio through logistic regression analysis in our meta-analysis. Consequently, this hindered us from actually developing a new prediction model of hypertension cure rate of unilateral adrenalectomy. In follow-up 
studies, large-sample clinical trials are still required to verify these potential preoperative predictors and their utility. In doing so, an effective prediction model of hypertension cure rate of unilateral adrenalectomy will be created.

Although this meta-analysis includes more studies and studies with larger sample sizes than individual studies, there were some limitations of this meta-analysis that might affect the outcome. First, the study was limited to articles that were published in English and Chinese. In addition, the unpublished studies that were not included may have caused a potential bias. It is possible that this could have resulted in the exclusion of several articles pertaining to the hypertension cure rate of unilateral adrenalectomy. Secondly, this research does have publication bias. Thirdly, selection bias of PA patients cannot be fully excluded, resulting from the inclusion of the method of diagnosis of unilateral disease. A part of PA patients don't be performed adrenalectomy for want of a clear diagnosis. For another, cure of hypertension is likely to depend at least in part on what is left in the remaining adrenal. Thus high-precision imaging and AVS should be used to improve diagnostic accuracy. Fourthly, most original studies do not report post-operative aldo-renin ratios and as such, biochemical cure cannot be ascertained. Lastly, extreme heterogeneity was present in this study and although groups were stratified, heterogeneity still persisted.

\section{Conclusions}

The hypertension cure rate of unilateral adrenalectomy in PA was assessed by meta-analysis and the results indicate that the hypertension cure rate is not high. We could not obtain a pooled odds ratio through logistic regression analysis by the method of meta-analysis because of inconsistent data pertaining to risk factors and outcome. Given the limitations of the included studies, particularly detection bias, large-sample clinical trials are required to verify the rationale of potential preoperative predictors in developing a new and effective prediction model.

\section{Abbreviations}

ACl: abdominal calcification index; APA: aldosterone-producing adenoma; ARS: aldosteronoma resolution score; AVS: adrenal vein samplings; BMI: Body mass index; CNKI: China National Knowledge Internet; DBP: diastolic blood pressure; IHA: Idiopathic hyperaldosteronism; LDL: Low Density Lipoprotein: LVM: Left Ventricular Mass; LVMI: Left Ventricular Mass Index; MOOSE: Metaanalysis Of Observational Studies in Epidemiology; PA: primary aldosteronism: PAC: plasma aldosterone concentration; SBP: systolic blood pressure

\section{Acknowledgments}

None.

\section{Funding}

This study did not get any form of funding.

\section{Authors' contributions}

YZ and LBL conceived the idea of the review. YZ, MLZ and SJK conducted the review. The initial draft of the manuscript was prepared by $Y Z$ and all authors (YZ, MLZ, SJK, and LBL) critically revised article drafts and approved the final version. LBL is the guarantor of this paper.

\section{Ethics approval and consent to participate}

This study did not require ethics approval or participant consent given the nature of the work undertaken.

\section{Consent for publication}

Not applicable

\section{Competing interests}

The authors declare that they have no competing interests.

\section{Publisher's Note}

Springer Nature remains neutral with regard to jurisdictional claims in published maps and institutional affiliations.

\section{Author details}

'Department of Endocrinology, Fujian Medical University Union Hospital, Fuzhou, Fujian 350001, China. 'Department of Ultrasonography, Fujian Medical University Union Hospital, Fuzhou, Fujian 350001, China.

Received: 1 December 2016 Accepted: 12 September 2017 Published online: 03 October 2017

\section{References}

1. Funder JW, Carey RM, Mantero F, Murad MH, Reincke M, Shibata H, Stowasser M, Young WF Jr. The Management of Primary Aldosteronism: case detection, diagnosis, and treatment: an Endocrine Society clinical practice guideline. J Clin Endocrinol Metab. 2016;101(5):1889-916.

2. Hannemann A, Wallaschofski H. Prevalence of primary aldosteronism in patient's cohorts and in population-based studies-a review of the current literature. Horm Metab Res. 2012;44(3):157-62.

3. Schwartz GL, Turner ST. Screening for primary aldosteronism in essential hypertension: diagnostic accuracy of the ratio of plasma aldosterone concentration to plasma renin activity. Clin Chem. 2005;51(2):386-94.

4. Hannemann A, Bidlingmaier M, Friedrich N, Manolopoulou J, Spyroglou A, Volzke H, Beuschlein F, Seissler J, Rettig R, Felix SB, et al. Screening for primary aldosteronism in hypertensive subjects: results from two German epidemiological studies. Eur J Endocrinol. 2012;167(1):7-15.

5. Rossi GP, Cesari M, Cuspidi C, Maiolino G, Cicala MV, Bisogni V, Mantero F, Pessina AC. Long-term control of arterial hypertension and regression of left ventricular hypertrophy with treatment of primary aldosteronism. Hypertension. 2013:62(1):62-9.

6. Omura M, Sasano H, Saito J, Yamaguchi K, Kakuta Y, Nishikawa T. Clinical characteristics of aldosterone-producing microadenoma, macroadenoma, and idiopathic hyperaldosteronism in 93 patients with primary aldosteronism. Hypertens Res. 2006;29(11):883-9.

7. Zarnegar R, Young WF Jr, Lee J, Sweet MP, Kebebew E, Farley DR, Thompson GB, Grant CS, Clark OH, Duh QY. The aldosteronoma resolution score: predicting complete resolution of hypertension after adrenalectomy for aldosteronoma. Ann Surg. 2008;247(3):511-8.

8. Wu VC, Chueh SC, Chang HW, Lin LY, Liu KL, Lin YH, Ho YL, Lin WC, Wang SM, Huang KH, et al. Association of kidney function with residual hypertension after treatment of aldosterone-producing adenoma. Am J Kidney Dis. 2009;54(4):665-73.

9. Xie LF, Ouyang JZ, Wang AP, Wang WB, Li XT, Wang BJ, Mu YM. Gene expression profile of persistent postoperative hypertension patients with aldosterone-producing adenomas. Chin Med J. 2015;128(12):1618-26.

10. Benham JL, Eldoma M, Khokhar B, Roberts DJ, Rabi DM, Kline GA. Proportion of Patients With Hypertension Resolution Following Adrenalectomy for Primary Aldosteronism: A Systematic Review and Meta-Analysis. J Clin Hypertens (Greenwich). 2016;18(12):1205-12.

11. Sang X, Jiang Y, Wang W, Yan L, Zhao J, Peng Y, Gu W, Chen G, Liu W, Ning $G$. Prevalence of and risk factors for primary aldosteronism among patients with resistant hypertension in China. J Hypertens. 2013:31(7):1465-71. discussion 1471-1462 
12. Stroup DF, Berlin JA, Morton SC, Olkin I, Williamson GD, Rennie D, Moher D, Becker BJ, Sipe TA, Thacker SB. Meta-analysis of observational studies in epidemiology: a proposal for reporting. Meta-analysis of observational studies in epidemiology (MOOSE) group. JAMA. 2000;283(15):2008-12.

13. Higgins JP, Thompson SG. Quantifying heterogeneity in a meta-analysis. Stat Med. 2002:21(11):1539-58.

14. Higgins JP, Thompson SG, Deeks JJ, Altman DG. Measuring inconsistency in meta-analyses. BMJ (Clinical research ed). 2003;327(7414):557-60.

15. Horita Y, Inenaga T, Nakahama H, Ishibashi-Ueda H, Kawano Y, Nakamura S, Horio T, Okuda N, Ando M, Takishita S. Cause of residual hypertension after adrenalectomy in patients with primary aldosteronism. Am J Kidney Dis. 2001;37(5):884-9.

16. Sawka AM, Young WF, Thompson GB, Grant CS, Farley DR, Leibson C, van Heerden JA. Primary aldosteronism: factors associated with normalization of blood pressure after surgery. Ann Intern Med. 2001;135(4):258-61.

17. Fukudome Y, Fujii K, Arima H, Ohya Y, Tsuchihashi T, Abe I, Fujishima M. Discriminating factors for recurrent hypertension in patients with primary aldosteronism after adrenalectomy. Hypertens Res. 2002;25(1):11-8.

18. Rossi H, Kim A, Prinz RA. Primary hyperaldosteronism in the era of laparoscopic adrenalectomy. Am Surg. 2002;68(3):253-6. discussion 256-257

19. Tan YW, Liu NB, Luo J, Jiang YJ, M Z. Diagnosis and treatment of primary aldosteronism (report of 46 cases). J China-Japan Friendship Hospital. 2002;16(3):149-51.

20. Goh BK, Tan YH, Yip SK, Eng PH, Cheng CW. Outcome of patients undergoing laparoscopic adrenalectomy for primary hyperaldosteronism. JSLS. 2004;8(4):320-5.

21. Meyer A, Brabant G, Behrend M. Long-term follow-up after adrenalectomy for primary aldosteronism. World J Surg. 2005;29(2):155-9.

22. Han QH, Wei JX, Zhang XP, Zhang WX, Wang ZY, Wu YD, JG G. Transperitoneal laparoscopic procedure for primary aldosteronism:report of 47 cases. Clinical Medicine. 2006;26(4):3-4.

23. Pang TC, Bambach C, Monaghan JC, Sidhu SB, Bune A, Delbridge LW, Sywak MS. Outcomes of laparoscopic adrenalectomy for hyperladosteronism. ANZ J Surg. 2007;77(9):768-73.

24. Ziaja J, Chudek J, Krol R, Pawlicki J, Wiecek A, Cierpka L. Rare normalization of blood pressure after unilateral adrenalectomy in 31 patients with conn syndrome. Langenbecks Arch Surg. 2007;392(4):431-5.

25. Walz MK, Gwosdz R, Levin SL, Alesina PF, Suttorp AC, Metz KA, Wenger FA, Petersenn S, Mann K, Schmid KW. Retroperitoneoscopic adrenalectomy in Conn's syndrome caused by adrenal adenomas or nodular hyperplasia. World J Surg. 2008;32(5):847-53.

26. White ML, Gauger PG, Doherty GM, Cho KJ, Thompson NW, Hammer GD, Miller BS. The role of radiologic studies in the evaluation and management of primary hyperaldosteronism. Surgery. 2008;144(6):926-33. discussion 933

27. Mourad JJ, Girerd X, Milliez P, Lopez-Sublet M, Lejeune S, Safar ME. Urinary aldosterone-to-active-renin ratio: a useful tool for predicting resolution of hypertension after adrenalectomy in patients with aldosterone-producing adenomas. Am J Hypertens. 2008;21(7):742-7.

28. Chiou TT, Chiang PH, Fuh M, Liu RT, Lee WC, Lee WC, Ng HY, Tsai YC, Chuang FR, Huang CC, et al. Factors determining cardiovascular and renal outcomes after adrenalectomy in patients with aldosterone-producing adrenal adenoma. Tohoku J Exp Med. 2009;218(1):17-24.

29. Campagnacci R, Crosta F, De Sanctis A, Baldarelli M, Giacchetti G, Paganini AM, Coletta M, Guerrieri M. Long-term results of laparoscopic adrenalectomy for primary aldosteronism. J Endocrinol Investig. 2009;32(1):57-62.

30. Wang B, Zhang G, Ouyang J, Deng X, Shi T, Ma X, Li H, Ju Z, Wang C, Wu Z, et al. Association of DNA polymorphisms within the CYP11B2/CYP11B1 locus and postoperative hypertension risk in the patients with aldosteroneproducing adenomas. Urology. 2010;76(4):1018. e1011-1017

31. Tresallet C, Salepcioglu H, Godiris-Petit G, Hoang C, Girerd X, Menegaux F. Clinical outcome after laparoscopic adrenalectomy for primary hyperaldosteronism: the role of pathology. Surgery. 2010;148(1):129-34.

32. Mathur A, Kemp CD, Dutta U, Baid S, Ayala A, Chang RE, Steinberg SM, Papademetriou V, Lange E, Libutti SK, et al. Consequences of adrenal venous sampling in primary hyperaldosteronism and predictors of unilateral adrenal disease. J Am Coll Surg. 2010;211(3):384-90.

33. Kim RM, Lee J, Soh EY. Predictors of resolution of hypertension after adrenalectomy in patients with aldosterone-producing adenoma. J Korean Med Sci. 2010;25(7):1041-4

34. Fu B, Zhang X, Wang GX, Lang B, Ma X, Li HZ, Wang BJ, Shi TP, Ai X, Zhou $H X$, et al. Long-term results of a prospective, randomized trial comparing retroperitoneoscopic partial versus total adrenalectomy for aldosterone producing adenoma. J Urol. 2011;185(5):1578-82.
35. Waldmann J, Maurer L, Holler J, Kann PH, Ramaswamy A, Bartsch DK, Langer P. Outcome of surgery for primary hyperaldosteronism. World J Surg. 2011;35(11):2422-7.

36. Tang KL, Lin $Y, L m L$. Laparoscopic management of primary aldosteronism: a report of 227 cases. Chin J Endocr Surg. 2011;5(2):117-9.

37. Wang ZS, Wang CY, H H. Clinical analysis of 32 cases with primary aldosteronism. HAINAN MEDICAL JOURNAL. 2011;22(4):9-11.

38. Van Der Linden P, Steichen $\mathrm{O}$, Zinzindohoué F, Plouin PF. Blood pressure and medication changes following adrenalectomy for unilateral primary aldosteronism: a follow-up study. J Hypertens. 2012;30(4):761-9.

39. Wang W, Hu WL, Zhang LC, Xiao YS, Liu J, Bin C. Polymorphic variation of CYP11B2 predicts postoperative resolution of hypertension in patients undergoing adrenalectomy for aldosterone-producing adenomas. Int J Urol. 2012;19(9):813-20.

40. LW. The laparoscopic surgical treatment of primary aldosteronism. Chin J Endocr Surg. 2012;6(4):260-4

41. Wang YG, Wang Q, Qi FB, Ya LK, Liu L, Shi ZF, M S. Clinical diagnosis and analysis of primary aldosteronism: a report of 83 cases. Journal of Chinese Physician. 2012;14(10):1417-9.

42. Zhang X, Zhu Z, Xu T, Shen Z. Factors affecting complete hypertension cure after adrenalectomy for aldosterone-producing adenoma: outcomes in a large series. Urol Int. 2013;90(4):430-4.

43. Aronova A, Gordon BL, Finnerty BM, Zarnegar R, Fahey TJ 3rd. Aldosteronoma resolution score predicts long-term resolution of hypertension. Surgery. 2014;156(6):1387-92. discussion 1392-1383

44. Jiang SB, Guo XD, Wang HB, Gong RZ, Xiong H, Wang Z, Zhang HY, Jin XB. A retrospective study of laparoscopic unilateral adrenalectomy for primary hyperaldosteronism caused by unilateral adrenal hyperplasia. Int Urol Nephrol. 2014:46(7):1283-8.

45. Lim V, Guo Q, Grant CS, Thompson GB, Richards ML, Farley DR, Young WF Jr. Accuracy of adrenal imaging and adrenal venous sampling in predicting surgical cure of primary aldosteronism. J Clin Endocrinol Metab. 2014;99(8):2712-9.

46. Wachtel H, Cerullo I, Bartlett EK, Kelz RR, Cohen DL, Karakousis GC, Roses RE, Fraker DL. Long-term blood pressure control in patients undergoing adrenalectomy for primary hyperaldosteronism. Surgery. 2014;156(6): 1394-402 discussion1402-1393

47. Hartmann I, Grepl M, Vidlar A, Smakal O, Vaclavik J, Frysak Z, Dolezel M, Student $\mathrm{V}$. Outcomes of adrenalectomy in patients with primary hyperaldosteronism-a single centre experience. Biomed Pap Med Fac Univ Palacky Olomouc Czech Repub. 2014;158(4):583-90.

48. Utsumi T, Kamiya N, Endo T, Yano M, Kamijima S, Kawamura K, Imamoto T, Naya $Y$, Ichikawa T, Suzuki H. Development of a novel nomogram to predict hypertension cure after laparoscopic adrenalectomy in patients with primary aldosteronism. World J Surg. 2014;38(10):2640-4.

49. Wolley MJ, Gordon RD, Ahmed AH, Stowasser M. Does contralateral suppression at adrenal venous sampling predict outcome following unilateral adrenalectomy for primary aldosteronism? A retrospective study. J Clin Endocrinol Metab. 2015;100(4):1477-84.

50. $\mathrm{Hu}$ YH, Wu CH, Er LK, Lin CD, Liu YB, Chueh SC, Tsai YC. Laparoendoscopic single-site adrenalectomy in patients with primary hyperaldosteronism: a prospective study with long-term follow up. Asian J Surg. 2015.

51. Citton M, Viel G, Rossi GP, Mantero F, Nitti D, lacobone M. Outcome of surgical treatment of primary aldosteronism. Langenbecks Arch Surg. 2015;400(3):325-31.

52. Volpe C, Hamberger B, Höög A, Mukai K, Calissendorff J, Wahrenberg H, Zedenius J, Thorén M. Primary aldosteronism: functional histopathology and long-term follow-up after unilateral adrenalectomy. Clin Endocrinol. 2015;82(5):639-47.

53. Fujita $\mathrm{N}$, Hatakeyama S, Yamamoto $\mathrm{H}$, Imai A, Yoneyama T, Hashimoto $\mathrm{Y}$, Koie T, Ohyama C: The implication of aortic calcification on persistent hypertension after laparoscopic adrenalectomy in patients with primary aldosteronism. European Urology, Supplements 2016, 15(3):e486.

54. Steichen O, Zinzindohoue F, Plouin PF, Amar L. Outcomes of adrenalectomy in patients with unilateral primary aldosteronism: a review. Horm Metab Res 2012:44(3):221-7.

55. Catena C, Colussi G, Nadalini E, Chiuch A, Baroselli S, Lapenna R, Sechi LA Cardiovascular outcomes in patients with primary aldosteronism after treatment. Arch Intern Med. 2008;168(1):80-5.

56. Milliez P, Girerd X, Plouin PF, Blacher J, Safar ME, Mourad JJ. Evidence for an increased rate of cardiovascular events in patients with primary aldosteronism. J Am Coll Cardiol. 2005;45(8):1243-8. 
57. Muiesan ML, Salvetti M, Paini A, Agabiti-Rosei C, Monteduro C, Galbassin G, Belotti E, Aggiusti C, Rizzoni D, Castellano M, et al. Inappropriate left ventricular mass in patients with primary aldosteronism. Hypertension. 2008:52(3):529-34

58. Liu G, Yin GS, Tang JY, Ma DJ, Ru J, Huang XH. Endothelial dysfunction in patients with primary aldosteronism: a biomarker of target organ damage. J Hum Hypertens. 2014;28(12):711-5.

59. Lee HH, Hung CS, Wu XM, Wu VC, Liu KL, Wang SM, Lin LC, Chen PC, Guo YL, Chueh SC, et al. Myocardial ultrasound tissue characterization of patients with primary aldosteronism. Ultrasound Med Biol. 2013;39(1):54-61.

Submit your next manuscript to BioMed Central and we will help you at every step:

- We accept pre-submission inquiries

- Our selector tool helps you to find the most relevant journal

- We provide round the clock customer support

- Convenient online submission

- Thorough peer review

- Inclusion in PubMed and all major indexing services

- Maximum visibility for your research

Submit your manuscript at www.biomedcentral.com/submit 